\title{
Experiencias ocultas: sobre lo humano en la capilla de San José en Sevilla
}

Tomas García García

Universidad de Sevilla (España)

Francisco Javier Montero-Fernández

Universidad de Sevilla (España) 



\title{
Experiencias ocultas: sobre lo humano en la capilla de San José en Sevilla
}

\section{Hidden experiences: about the human in the San Jose chapel in Seville}

\author{
Tomas García García \\ Universidad de Sevilla (España) \\ tgarcia@us.es
}

Francisco Javier Montero-Fernández

Universidad de Sevilla (España)

fmontero@us.es

Fecha de recepción: 23 de septiembre de 2018

Fecha de aceptación: 03 de abril de 2020

\begin{abstract}
Resumen
Vivimos refugiados en mundos desdoblados que inventamos sin saberlo, en sus sombras naturales; y cuando la naturaleza no basta, lo corregimos con arquitectura, que es el arte y la técnica de las sombras arrojadas, un lugar al que sin duda pertenecemos de lleno.

La luz nos es dada, la sombra no. El mundo que nos rodea se divide en dos mitades irreconocibles, la luz y las tinieblas, como inocente expresión de dos espacios aparentemente opuestos: el cielo y la tierra. Nacemos dándonos a la luz, pero vivimos refugiados en sus sombras negras.

La humanidad busca con obsesión el encuentro con estas experiencias ocultas, para observar la vida desde el otro lado. Esta pequeña capilla del barroco sevillano, conserva oculta en el trasfondo de su masa un misterioso secreto. A través de los ojos de dos jóvenes estudiantes de arquitectura de los años 60, nos adentraremos en un mundo invisible y humano (figura 1).
\end{abstract}

Palabras claves: Espacio oculto; Escenografía; Invisibilidad; Barroco sevillano

\footnotetext{
Abstract

We live as refugees in concentric worlds that we invent without know it, by their natural shadows; and when nature isn't enough, we correct it with architecture which is the art and technique of those casting shadows, a place in which we undoubtedly belong to.
} 
Light is given to us, shadow is not. The world that surrounds us is divided into two unrecognizable halves, light and darkness, as an innocent expression of two opposing spaces: sky and earth. We are born giving ourselves to light, but we live sheltered in the darkness to which we belong, in their black shadows.

Humanity search obsessively to encounter these hidden shadows, to let us the observation of life from the other side. This small sevillian baroque chapel preserves, hidden its inner mass, a mysterious secret. Through the eyes of these young architecture students, we enter a fascinating and unknown world.

Keywords: Hidden space; Scenery; Invisibility; Sevillian Baroque

\section{ANTEGEDENTES. CARPINTEROS DE LO BLANCO, 1571-1766.}

La Capilla de San José, también llamada de los Carpinteros, es uno de los espacios más representativos del barroco sevillano. Aunque existe constancia documental de la actividad de los carpinteros en Sevilla desde el siglo XIV, la organización de su trabajo, su influencia en la construcción de estos espacios y el funcionamiento del Gremio no puede ser constatada hasta 1527, fecha de la publicación de las Ordenanzas de Sevilla. En aquel tiempo, el Gremio de los Carpinteros de lo Blanco, en contraposición con el de los de Rivera o Calafates, dedicados a las labores de astilleros, se componía de cuatro grupos, especializados por su tipología de trabajo.

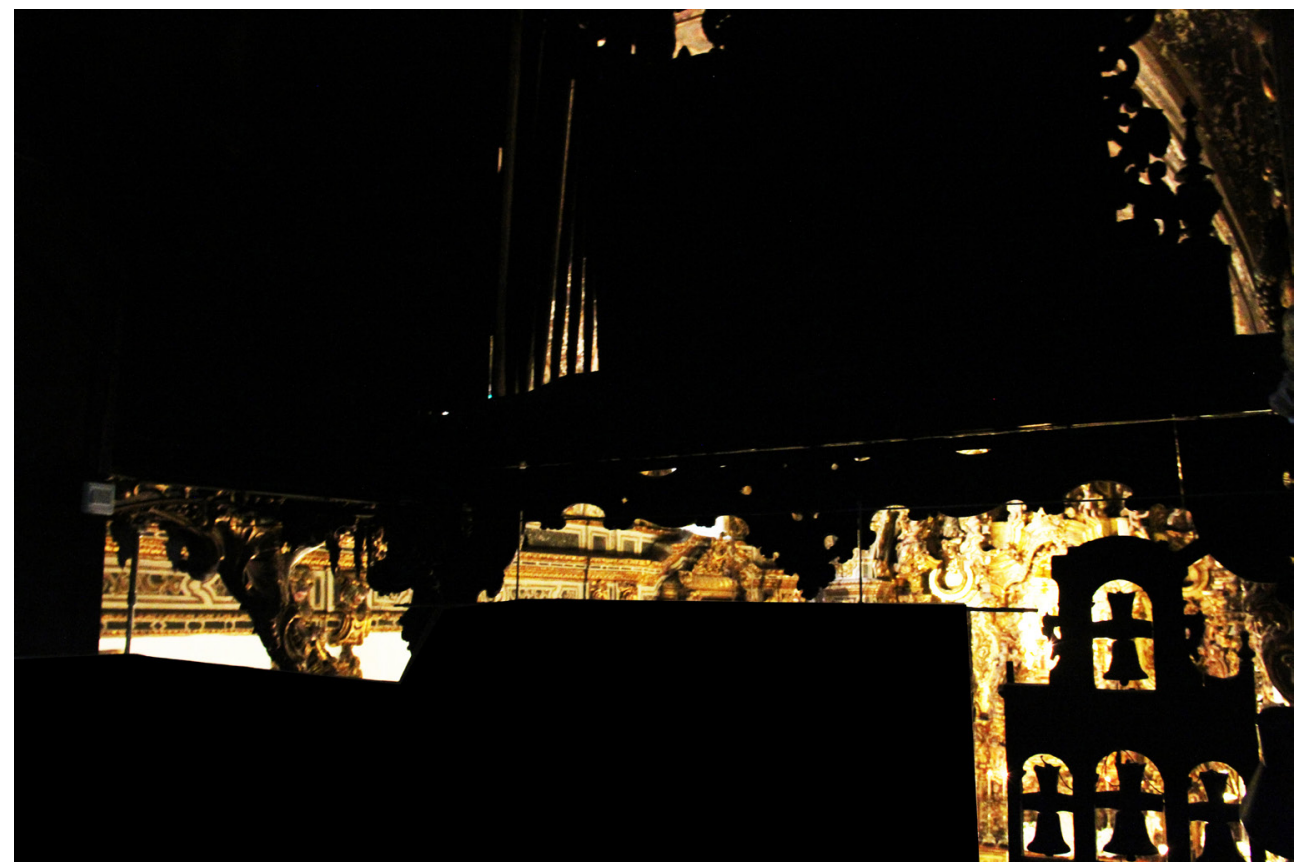

Fig. 1. La Capilla de San José, Sevilla. Fotografía tomada por el autor, 2015. Fotografía ganadora del "Primer Concurso fotográfico Capilla de San José en Sevilla", 
El de lo Blanco, dividido entre los de armar, al ser los constructores de las complejas cubiertas de madera, y los de tienda, ocupados en labores más cercanas a la actual ebanistería, que tendrán sus propias ordenanzas desde 1533. El de lo Prieto, expertos en ingenios para oficios y utilidades; el de los Violeros, dedicados a la elaboración de los instrumentos musicales con cajas de resonancia, y el de los Entalladores, consagrados a la construcción de retablos, sillerías de coro, sagrarios y monumentos funerarios. El gremio no solo se encargaba de la organización de los carpinteros y su promoción, de la defensa de sus intereses, sino también garantizaba el trabajo entre sus miembros y el desarrollo de su bienestar económico y social. En 1571, se crea la Hermandad de los Siete Dolores y Gozos de Nuestro Santo Patriarca San José, que atendía a sus necesidades espirituales y al auxilio social de los pobres, viudas o huérfanos de los miembros del gremio.

Las reuniones de la corporación se realizaban en el hospital de Dios Padre, San Felipe y Santiago, en el mismo emplazamiento que hoy se levanta la Capilla de San José. El edificio, de ladrillos enfoscados y encalados, contaba con un amplio zaguán de acceso, donde se realizaban los cabildos; un patio central, en torno al cual se disponían las estancias en doble altura, y una pequeña capilla. Casi setenta años más tarde, en 1647, el estado de su fábrica era tan alarmante que tuvo que repararse, dirigiendo la reforma el carpintero Luis Díaz. Éstas no resultaron suficientes, pues en 1687 se intervino nuevamente ante el inminente desplome de su fachada principal. Las obras comenzaron al año siguiente, terminándose en 1701, siendo éstas el origen de la actual capilla.

Según Cruz Isidoro (2015, p. 19), tras el derribo de las fachadas a la calle Jovellanos, "se levantó el templo, de una sola nave, cubierta por una estructura de madera y una falsa bóveda de cañón con arcos fajones y lunetos, y con capilla mayor semicircular con bóveda de cuarto de esfera". El presbiterio, adornado con gradas de mármol rojo, fue presidido por el antiguo retablo mayor, realizado en 1627 por el maestro entallador Luis de Figueroa, del que actualmente nada se conserva.

La devoción a San José se incrementó considerablemente a lo largo de los siglos XVII y XVIII, lo que dificultó, debido a las reducidas dimensiones de la capilla, que los fieles pudiesen asistir a los cultos, especialmente en las grandes festividades en honor al Santo. Es la falta de espacio, la que lleva a los carpinteros a iniciar una nueva ampliación del templo, configurándose tal y como ha llegado a nuestros días. La decisión, según los datos que obran en poder del actual prior Fray Francisco, fue tomada en el cabildo del 18 de diciembre de $1746^{1}$,

"al disponer la compra de las casas que lindaban con el presbiterio y proceder a la construcción de una nueva capilla, mucho más profunda, dotándola de un crucero delantero, un camarín y un trasaltar. El diseño para la nueva zona será fruto de los

1 Libro de Cuentas, en Archivo Capilla de San José, Sevilla, p. 34 VI b. 
dictámenes de los hermanos, como por inteligentes en la arquitectura, por pertenecer a la carpintería la fábrica de edificios."

Se tomó como fuente de inspiración una ilustración de un libro, existente en la biblioteca de "una persona de distinción, en el que se recogían las obras de un alto arquitecto veneciano de acreditada nota". La dirección de las obras se la encomendaron al maestro albañil Esteban de Paredes. Fue precisamente las trazas de la ampliación lo que dividió al gremio de carpinteros en dos grupos enfrentados. Unos a favor del modelo propuesto, y otros, en contra del mismo, aludiendo a los errores de diseño producto de la intromisión de los carpinteros en las competencias de los maestros de albañilería. El litigio, que duró desde 1750 a 1753, ocasionó el retraso de la obra, si bien, los altos costes económicos de la misma y la escasez de

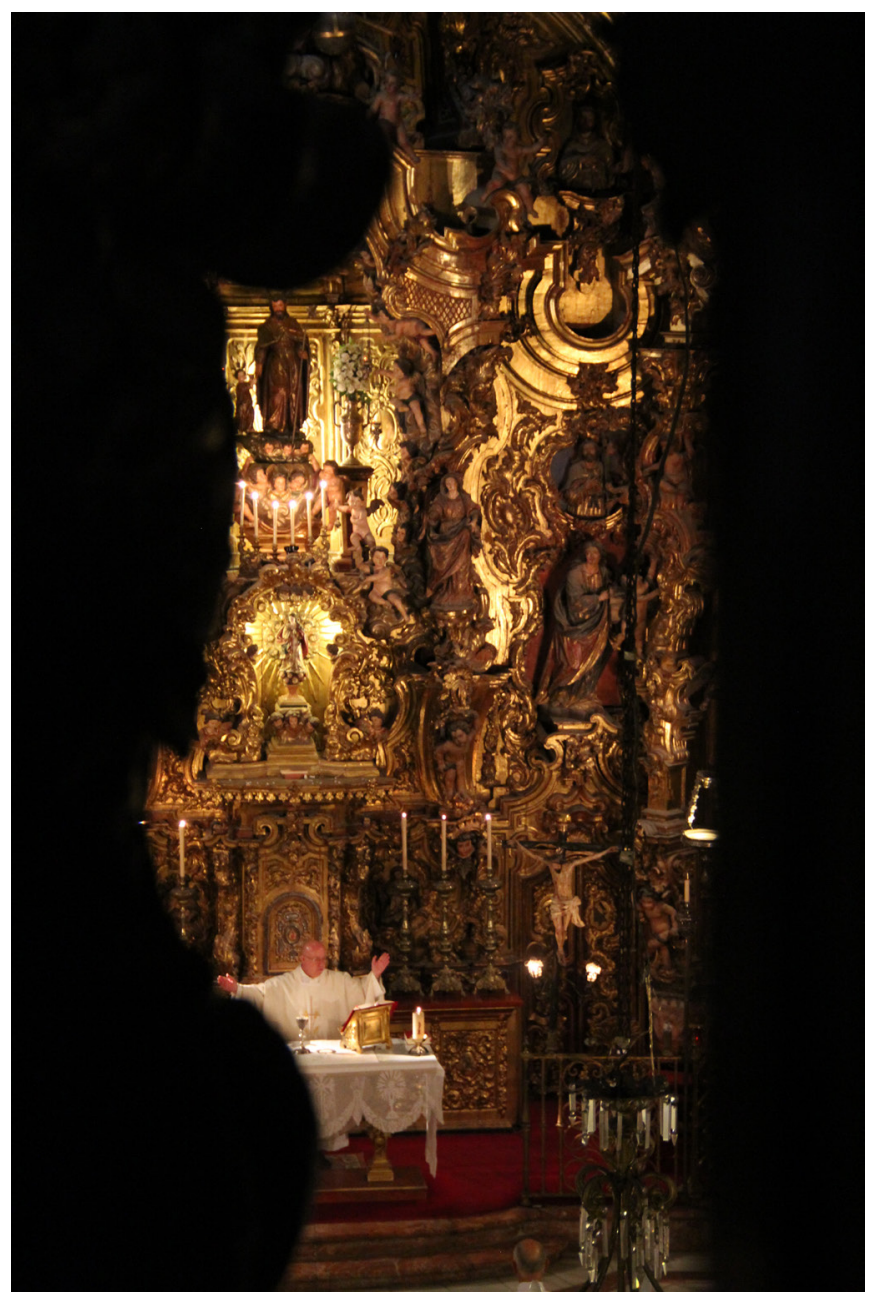

Fig. 2. La Capilla de San José, Sevilla. Trasfondo del órgano desde las dependencias capuchinas. Fotografía tomada por el autor, 2015. 


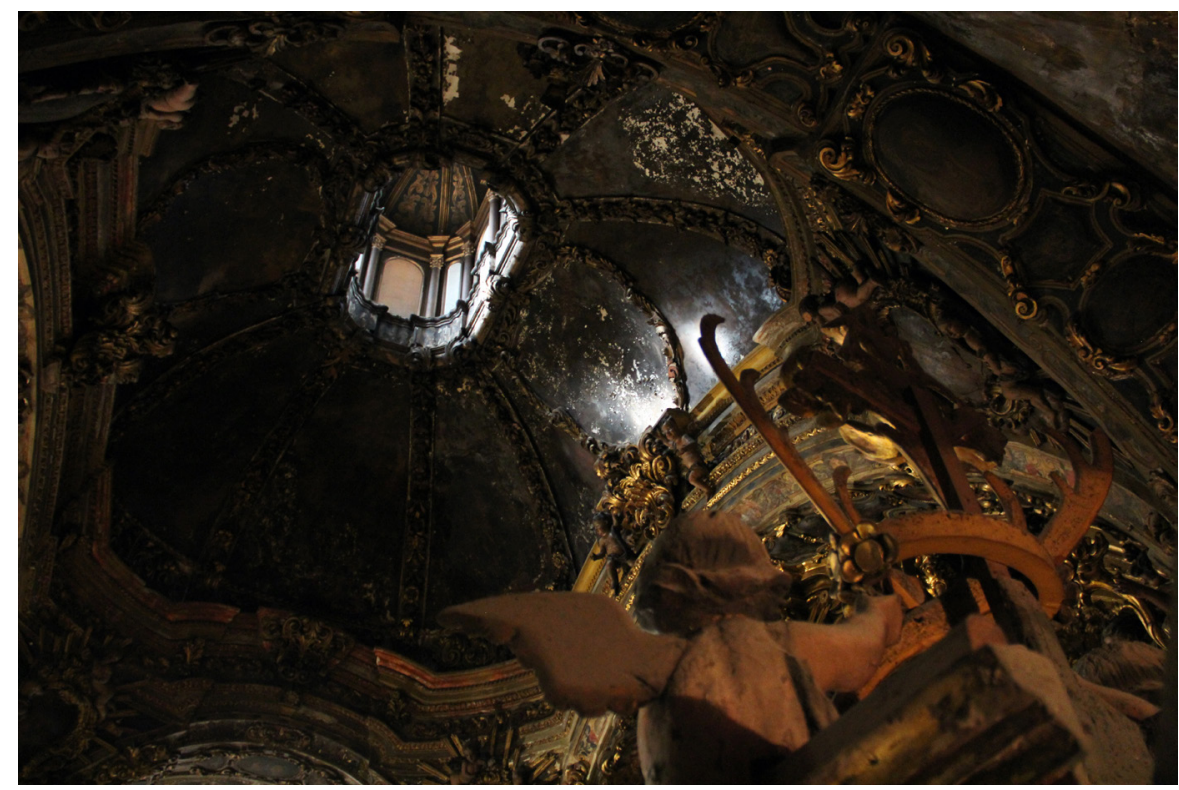

Fig. 3. La Capilla de San José, Sevilla. Cúpula desde las dependencias capuchinas. Fotografía tomada por el autor, 2015.

recursos, prolongó su finalización hasta 1766, con la incorporación de un tramo a los pies de la antigua iglesia y la construcción de la nueva fachada principal.

La capillita de San José sigue siendo para muchos sevillanos un pequeño refugio en madera, un secreto desvelado por la gubia con enorme destreza. El incendio sufrido en 1931 produjo daños terribles, con graves quemaduras en las pinturas murales y decoraciones de las bóvedas del crucero, retablos, y revestimientos decorativos. Desde entonces este espacio quedó marcado por el humo, oscurecida su talla para convertirse en una hermosa concavidad, un refugio en la ciudad, un recinto hueco, un escondite, un silencio ennegrecido por el fuego, una alcoba en la que cobijarse para desde ella combatir el mundo (figura 2 y 3 ).

\section{EXPERIENCIAS 1: LA PELICULA DE JOSE RAMON SIERRA DELGADO Y VICTOR PEREZ ESCOLANO, 1968.}

En 1968 dos jóvenes estudiantes de arquitectura, José Ramón Sierra Delgado y Víctor Pérez Escolano, rodaron una película que se encuentra en los fondos de la biblioteca de la Escuela de Arquitectura de la Universidad de Sevilla. El cortometraje, con el título de "Sobre la Capilla de San José en Sevilla", fue grabado en super-8 y formó parte de la Sección de Cine Experimental a cargo de Juan Sebastián Bollaín, 
dentro de la Cátedra de Estética que dirigía el catedrático Jaime López de Asiaín (Pérez Escolano y Sierra Delgado, 1968). ${ }^{2}$

La música de Handel construye un fondo sonoro sobre el que la imagen y la palabra se deslizan con soltura. Las palabras de Víctor Pérez Escolano conducen las imágenes de un lugar a otro, en una especie de azar aparente que muestra el espacio por partes, sin unidad, por escenas y lugares que interesan a José Ramón Sierra Delgado, que porta la cámara como un auténtico explorador de instantes.

La forma en la que se muestra el interior de la capilla mantiene una estrecha relación con su origen y construcción. La película comienza en la calle. Toldos, sombras y mucha gente impiden ver más allá de un palmo. Un muchacho que sale corriendo de una tienda tropieza con la cámara, unos niños saludan, una mujer que lleva su ropa limpia sonríe al cruzarse junto a ellos. La cámara se detiene en los detalles, acercándose y alejándose para contextualizar los fragmentos de aquella ciudad.

VP: En la Capilla de San José trabajaron los cofrades del gremio hispalense de carpinteros. Con su prestación personal, colaborando con ellos diversos maestros de obras. No existió en su realización un criterio unitario prefijado, es una obra sin arquitecto, realizada a lo largo de 80 años, que estuvo siempre en relación con la edificación colindante.

La capilla fue incendiada en los años previos a la guerra civil, las huellas del fuego están patentes en los techos. Haciendo una sintesis cronológica de la capilla existen dos etapas muy claras. Primera etapa 1690-1717, comprende la nave desde el crucero a los pies, las tribunas laterales de madera dorada y retablos laterales llamados "desposorios místicos" uno y "Santa Ana" el otro. Segunda etapa 1747-1766, comprende la portada y la capilla mayor, precedida de un crucero no trasdosado cubierto con bóveda de planta elíptica y con una linterna.

La voz se detiene y la cámara recorre el interior de la iglesia en busca de algo, moviéndose apresuradamente cerca de los objetos, desenfocándose en ocasiones, hasta detenerse en alguno de ellos, para iniciar de nuevo la búsqueda.

VP: Ligado a unas determinadas concepciones religiosas y aprendidos por los clásicos en la naturaleza, pero es el barroco culto de Borromini, nuestro barroco, con unos caracteres culturales más lejanos, con unas discutibles conexiones con el barroco italiano y el alemán, con el rococó. Borromini es el comienzo del espacio social investigado y determinado en cada momento. Ya no tiene sentido representar el espacio clásico.

2 Película inédita, realizada para la Sección de Cine Experimental de Arquitectura a cargo de Juan Sebastián Bollaín. Sección perteneciente a la Cátedra de Estética de la Escuela de Arquitectura de Sevilla (titular: Jaime López de Asiaín). Película original grabada en súper 8mm. Duración: 15m. La película ha sido digitalizada con motivo de esta investigación, y se conserva en DVD en la Biblioteca de la Escuela de Arquitectura de Sevilla. 
La imagen en este punto se funde a casi negro, tan solo algunos destellos luminosos acompañan las palabras de Víctor Pérez Escolano. La cámara se introduce en un lugar a oscuras, al fondo una luz tímida que escasamente ilumina la escena, brillos dorados y una extraña forma que parece indicarnos que estamos en el interior de uno de los gruesos muros perimetrales. La cámara avanza y de repente un sonido nos devuelve al espacio real, es como un zumbido intenso que obliga a Víctor a detener su narración. La imagen vuelve al interior de la iglesia y Víctor prosigue con su relato.

VP: Surge un espacio nuevo, unificado y continuo, cambiante a lo largo del recorrido. Un espacio sin fin, oculto bajo esta intensa topografía. No, la decoración barroca no tiene una misión espacial determinada, o quizás sí. El espacio está físicamente limitado por esta decoración, han desaparecido las paredes... los planos.

La cámara gira sin sentido dando vueltas bajo ángeles, lámparas, alas y molduras. La imagen pierde el control del espacio en una especie de agujero negro que haciéndola girar la sumerge en el interior de la oscuridad. De nuevo un zumbido parece hacer alusión al hecho de atravesar una cierta frontera, quizás la que nos separa de lo invisible y oculto.

$V P$ : El resultado puede ser un espacio opresivo psíquicamente, el color negro, puede ser que un espacio barroco sea expansivo, tal vez expansivo hasta cierto punto. Alguien ve por otra parte una función representativa de una realidad extraterrestre, quizás una realidad celestial.

Hay que hablar del papel que el pueblo ha representado ante uno de los estilos de mayor trascendencia histórica para nosotros. Existe quizá una clara implicación hacia un éxtasis. Esto sería importante si fuera cierto. Se podría opinar que no, tal vez se trate de crear un clima donde sean fáciles las relaciones del hombre con dios, de un clima de devoción... tal vez, o tal vez se trate de un éxtasis obligatorio, no tener nada que ver con la realidad exterior. La arquitectura como uno de los medios culturales de mantenimiento de una situación social.

El barroco pasa de ser de una postura rebelde a una postura oficial, quizás el éxtasis colectivo consciente de un grupo. Pero existe una funcionalidad, los hombres realizan allí unos actos, el espacio puede modificarlos, no existe ninguna funcionalidad, no sé si el espacio puede modificar unos actos, hay que discutir un recinto religioso como hecho social y después plantear la vigencia de un recinto determinado, hay que hablar de la vida y la muerte de la arquitectura cuando hay algo que cambia a su alrededor.

Hay que hablar del suelo de la capilla. Yo creo que debería verse más suelo.

La capilla se llena de gente, la imagen recorre sus cabezas, siempre por detrás, reparando en los pequeños detalles de algunos peinados, mantillas negras, luto y 
lágrimas. La película incluye finalmente a los usuarios como un estrato más, siglos después de haber sido construido el edificio. La escena se funde a negro y termina.

Es 1968, faltan casi 20 años para aquel Simposio en Finlandia en el que Steven Holl y Juhani Pallasmaa compartirían por primera vez sus ideas sobre la fenomenología en la arquitectura (Holl, 2011, p. 36). Sin embargo, estos dos jóvenes estudiantes habían convertido esta pequeña capilla en un sugerente "laboratorio del patrimonio" en el que ensayar con sus sentidos. José Ramón Sierra Delgado y Víctor Pérez Escolano, Catedráticos hoy día de la Universidad de Sevilla, menguan su tamaño para capturar, en esta experiencia docente, una doble realidad. La curiosidad de sus autores explora cientos de lugares que aguardan ocultos en las arrugas de su piel interior.

Lo que intentaron estos dos jóvenes estudiantes resulta asombroso; la grabación, de escasos 15 minutos de duración, muestra la esencia misma de este lugar. José Ramón Sierra Delgado y Víctor Pérez Escolano hunden su cámara en el interior de la madera, menguan su tamaño para capturar una doble realidad. Frente al espacio único de la iglesia barroca, la película muestra un paisaje fragmentado, la curiosidad de sus autores explora cientos de lugares que aguardan ocultos en las plegaduras de este interior. Una forma de ver el espacio que el cortometraje sabe mostrar con sutileza; dos mundos que se entremezclan poniendo en contacto, de forma ambigua, una doble realidad arquitectónica.

Estas imágenes son en sí mismas una exploración. José Ramón Sierra toma la cámara y se acerca en busca de algo, al encuentro de ese espacio mágico que el carpintero Luis Díaz hundió para siempre en lo más profundo de su obra. Estas imágenes encierran algo, lo siguen con insistencia hasta capturar un aire hundido para siempre en la profundidad de la madera. Esta divertida experiencia juvenil, como la han calificado sus propios autores, no tiene la intención de mostrar nada; estas no son imágenes pensadas para mostrar el espacio de la capilla. Esta familia de imágenes muestra una acción, muestran la actitud con la que hay que enfrentarse a este espacio. El cámara se adentra en el interior del espacio en busca de no se sabe qué, sin mapas, sin planos ni prejuicios, tan solo con sus sentidos bien abiertos. De fondo la narración de Víctor Pérez Escolano pauta la búsqueda, guía al espectador en el conocimiento histórico del lugar. Mientras Víctor Pérez Escolano pone la voz en off, transformando la cadencia de sus palabras en péndulo de aquel espacio, José Ramón Sierra introduce la cámara en el espesor de la madera, reduciendo su tamaño para mostrarnos una especie de orografía vertical. "No hay paredes, no hay planos", afirma Víctor Pérez en el cortometraje, al tiempo que la cámara parece verse atrapada en el relieve que cubre el interior de la capilla, recogiendo los rastros y huellas dejadas por el tiempo en una madera ennegrecida por el humo. No hay un interés por mostrar la totalidad del espacio. No hay intención de mostrar ni una sola imagen general del interior de la iglesia. 
La manera de mirar de este cortometraje es seductora, unos nuevos ojos, una nueva visión de aquel lugar parcial y fragmentada, que se recrea, en la búsqueda y el encuentro de nuevas situaciones. En una especie de sismografía barroca de formas y geometrías, la cámara coquetea, haciéndonos reducir mentalmente nuestra escala para descubrir una visión del espacio sorprendente y nunca vista. La cámara se esconde en la sombra, se adentra en ese mundo desconocido y misterioso para mostrarnos la parte inferior del púlpito oratorio, un ojo, una oreja y la boca de un ángel, un bulto que parece un techo y que al alejarse termina siendo una enorme moldura. José Ramón Sierra se detiene para enfocar una pequeña puerta de madera

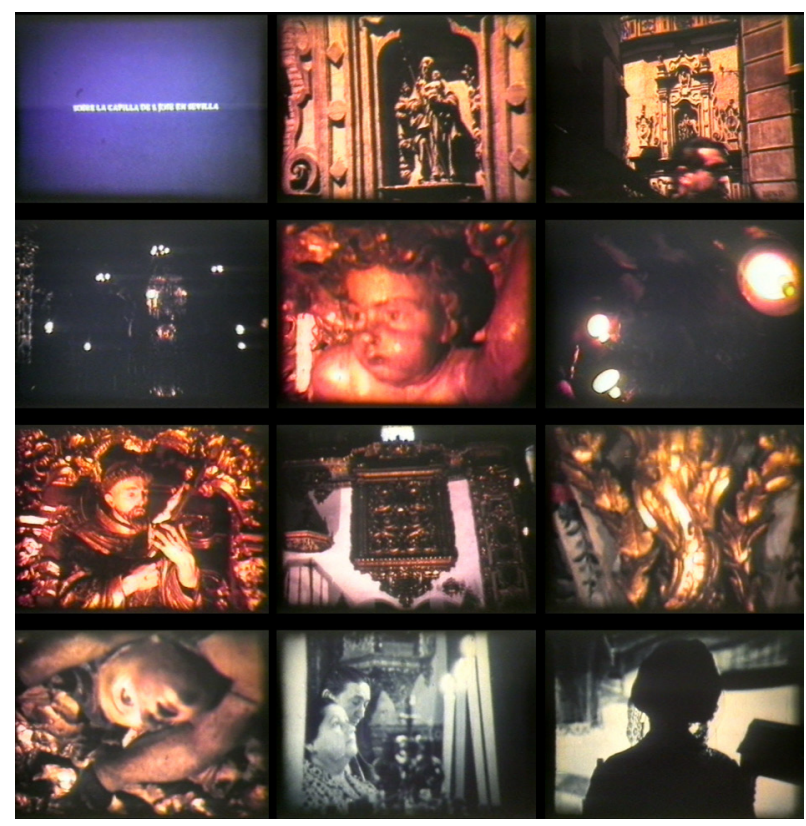

Fig. 4. Fotogramas de la película Sobre la Capilla de S. José en Sevilla, 1968. Autores: José Ramón Sierra Delgado y Víctor Pérez Escolano. (Película inédita. Digitalizada con motivo de esta investigación). La película se conserva en DVD en la Biblioteca de la Universidad de Sevilla, y bien merece su visita.

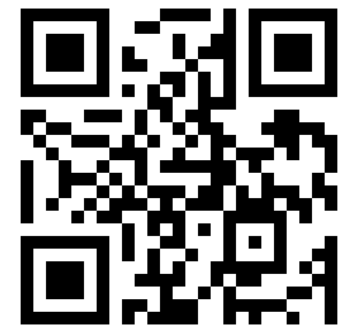

Fig 5. Código QR para el visionado de la película Sobre la Capilla de S. José en Sevilla, 1968. Autores: José Ramón Sierra Delgado y

Víctor Pérez Escolano.

que se esconde en una desviación de uno de los muros de fachada. Un pliegue en la materia que da acceso a una escalera que sube hasta una especie de mirador oculto tras una rejilla de madera. Se trata de una de las tribunas que, alojada en el interior de la masa, fue usada en su día como lugar de distancia e intimidad en la eucaristía (figuras 4 y 5 ). 


\section{EXPERIENCIAS 2: EL DIBUJO} DE LO OCULTO, 2015.

Durante la exploración realizada en el año 2015 junto al actual prior Fray Francisco, y en compañía de Juan Carlos Hernández, profesor del Dpto. de Historia del Arte de la Universidad de Sevilla, hemos encontrado varios espacios ocultos en la capilla; ocupan resquicios y fragmentos olvidados, hoy en día sellados para siempre por su falta de uso. Cientos de refugios nos esperan en la cara oculta de este mundo, cientos de lugares repletos de posibilidades proyectuales, desde los que aprender a observar de otra manera su patrimonio arquitectónico y artístico.

El levantamiento planimétrico de la capilla, inédito y realizado con motivo de esta investigación, muestra en planta una desviación geométrica entre los límites de la parcela y el vacío interior ocupado por la iglesia. Entre ambas formas se han instalado durante años las dependencias de los hermanos Capuchinos, con una curiosa relación visual entre ambos espacios. Este lugar es una escenografía, es una piel de madera troquelada por la gubia, tras la que se esconde la intensa vida de sus habitantes. Tras esta máscara, sagrada y oscura, se esconde otro espacio, un lugar lleno de actividad, un mundo rebosante de objetos domésticos, escaleras, habitaciones y lugares para el descanso. Esta cáscara de madera de alguna forma impide que sean percibidos, los protege del mundo exterior, del contacto con los otros, construyendo en sus sombras un lugar íntimo, de reflexión y tranquilidad. Parece desvelarse, por tanto, una cierta acción que pone en resonancia a estos habitantes, la voluntad de refugiarse y la
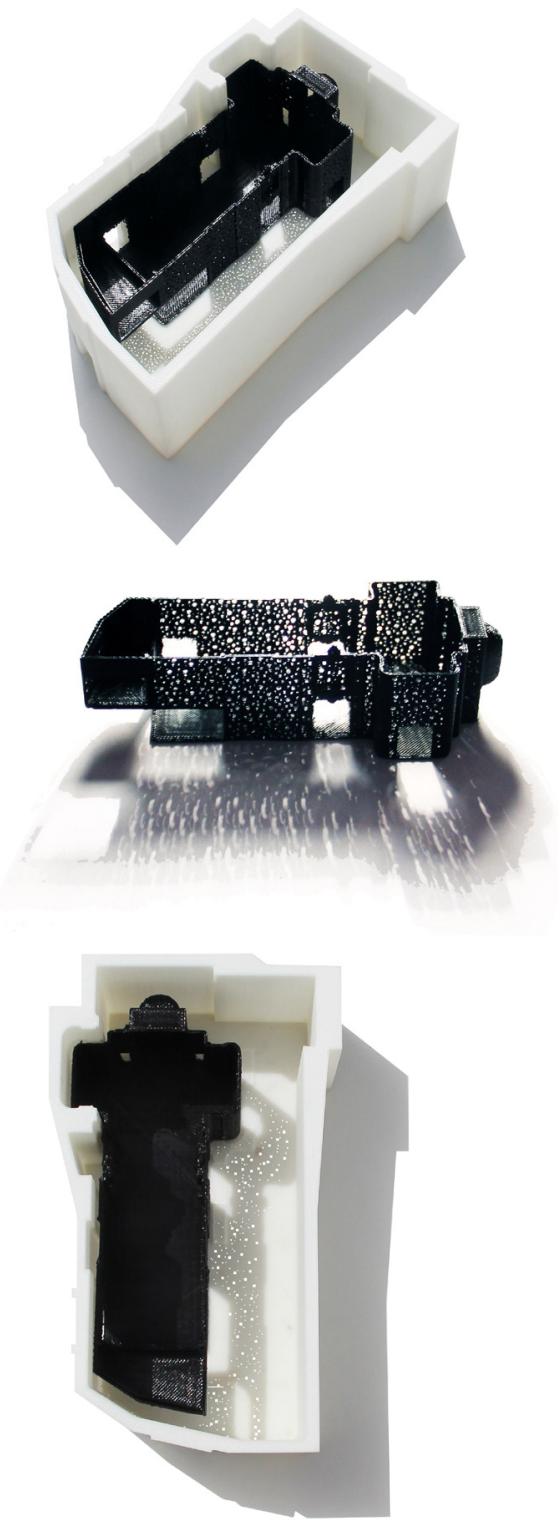

Figs. 6, 7a y 7b. La Capilla de San José, Sevilla, 2015. Interpretación de la envolvente de madera. En blanco el contenedor, en negro un contenido micro perforado. Durante años la comunidad de hermanos Capuchinos estuvo instalada en ese espacio intermedio. Maqueta de resina termo endurecida realizada en el FabLab de la ETSA, 2016. 
madera como cavidad. Pocos saben que, tras este lienzo sagrado, tras el dorado de su labra, hay un mundo oculto y humano, un espacio lleno de ojos que nos cuidan. Tras esta enorme celosía de madera se oculta la vida de la congregación, que sigue su día a día pendiente de lo que ocurre al otro lado (figuras 6, 7a y 7b).

Mientras que la iglesia está en uso, la actividad de la congregación cesa, nos referimos a la que se desarrolla en el espacio interior y oculto; se calman los ruidos, y se ralentizan los movimientos en una acción que usa los mecanismos de la ocultación. Al terminar la liturgia, las puertas de la iglesia se cierran, convirtiendo el espacio de la capilla en un bellísimo paisaje interior. Las ventanas de madera se abren, puertas y comportillos se despliegan, para convertir estas habitaciones en balcones hacia el vacío de la capilla. Estos lugares, alojados en el interior de la madera, estas sombras escondidas y hasta entonces ocultas, se iluminan a través de la propia iglesia, que se ha convertido de esta forma en un lujoso patio cubierto. Desde aquí dentro podemos trepar hasta alcanzar el altar mayor, aparecer de repente tras el mueble del órgano o deambular libremente por el interior de la madera (figura 8).

Entrenar nuestra mirada para descubrir nuevos lugares, pequeñas cuencas, vuelos y situaciones imposibles, geometrías que parecen animadas. Esta será nuestra cartografía para este espacio, detalles, encuentros, formas voluptuosas que juegan a confundir nuestro tamaño. Como en aquellos mapas de múltiples escalas dibujados por Belén Gopegui (2009, p. 45) con sus palabras, no queremos grandes planos, no buscamos el dibujo unitario del espacio, nos interesa el dibujo fragmentario, parcial que acompañe el camino abierto por la película. Un universo de formas recortadas en la madera, en las que, en una especie de juego de escalas subvertidas, una habitación
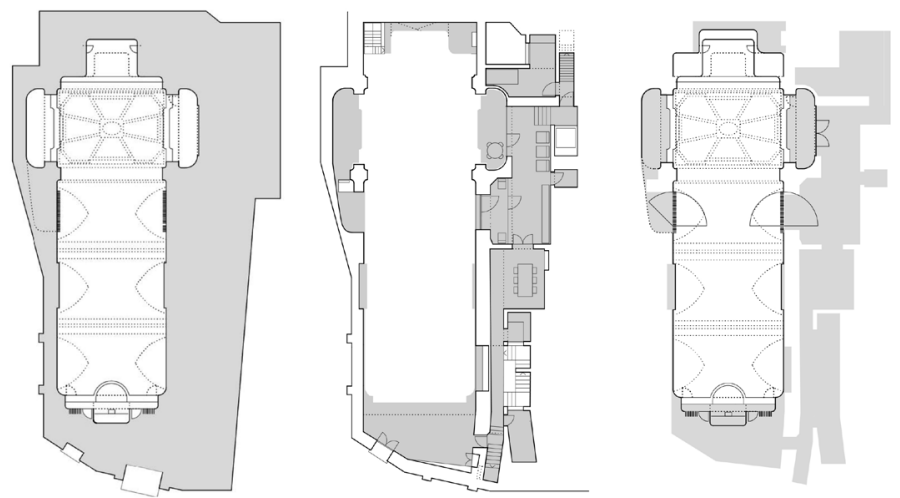

Fig. 8. La Capilla de San José, Sevilla, 2015. Envolvente de madera. Movimientos y pliegues de la carpintería; en gris masa y espacios domésticos alojados tras la madera. Planimetría inédita, realizada por el autor, 2016. 
puede surgir del encuentro entre dos rodillas, una mano sobrevuela protegiendo un suelo, o el brazo de un ángel se despliega para ofrecernos cobijo. Un lugar pequeño, pero básicamente lleno. Lleno de elementos tallados en los dorados, flores enroscadas y volutas, que dibujan en nuestra imaginación sucesivos acontecimientos que son capaces de sorprender a cualquiera, al ocultarse en el lienzo infinito que sirve de homenaje a esta exuberante carpintería de lo blanco.

\section{EXPERIENGIAS 3: CARTOGRAFIAS DEL ESPACIO OCULTO EN SEVILLA}

Al igual que otras criaturas literarias se desmaterializaron para asomarse a aquello que no se ve a simple vista, para desentrañar lo que no está en primer plano o para violentar la calma de los recintos más recónditos, este ensayo miniaturiza al lector para sumergirlo en lugares que la arquitectura de nuestra ciudad esconde celosamente en su interior; para profanar con su lupa los alveolos con los que esta respira (Parra, J., 2020, pp. 164-165).

Esta es la historia de una cartografía de lo oculto, en virtud de la cual una imagen, un dibujo, un relato o un mapa, traídos de un viaje a otro mundo, representan o significan la esencia de lo que realmente es. Escribir y dibujar esta Sevilla es hacerlo figuradamente, empleando imágenes para evocar espacios e ideas. Esta estrategia nos permitirá hacer visible lo que es abstracto, lo que de alguna forma permanece invisible a nuestros ojos. Cartografías de una Sevilla evocada desde la duplicidad, desde la diferencia entre la ciudad imaginada y su significado, que es lo que la hace susceptible de manipulación (Colomina, 2006, p. 102).

Reconozco que en este tiempo nos hemos convertido en algo más que en simples habitantes; nos hemos convertido en una especie de experimentadores del espacio. Ha resultado fascinante adentrarse en las entrañas de esta ciudad con la idea de registrar su acción. Como arquitecto y explorador de la arquitectura me considero un diletante, en el mismo sentido que un grupo de arquitectos y entusiastas del arte ingleses se bautizaron como societé dei dilettanti (McCall, 2008, p. 82), es decir me siento guiado por la curiosidad y la afición construida durante años por el descubrimiento de ciertos espacios. Con el tiempo he aprendido que una pequeña puerta abierta en un muro de cualquier edificio puede muchas veces conducir al descubrimiento de un espacio absolutamente insólito e inesperado.

Si algo he aprendido en estas deambulaciones arquitectónicas, en todos estos años de exploraciones y búsquedas, si algo quedó marcado en nosotros tras la experiencia vivida en el interior del Órgano de la Epístola de la Catedral de Sevilla, si aún nos emocionamos al recordar lo ocurrido al aproximarnos a la Sala De Profundis en el Convento de Santa Clara en Sevilla, si no olvidamos aquel instante eterno al sumergir nuestro cuerpo en el trasfondo de la Capilla de San José en Sevilla, es que el verdadero lujo del espacio está en sus partes ocultas. El espacio construido de la 

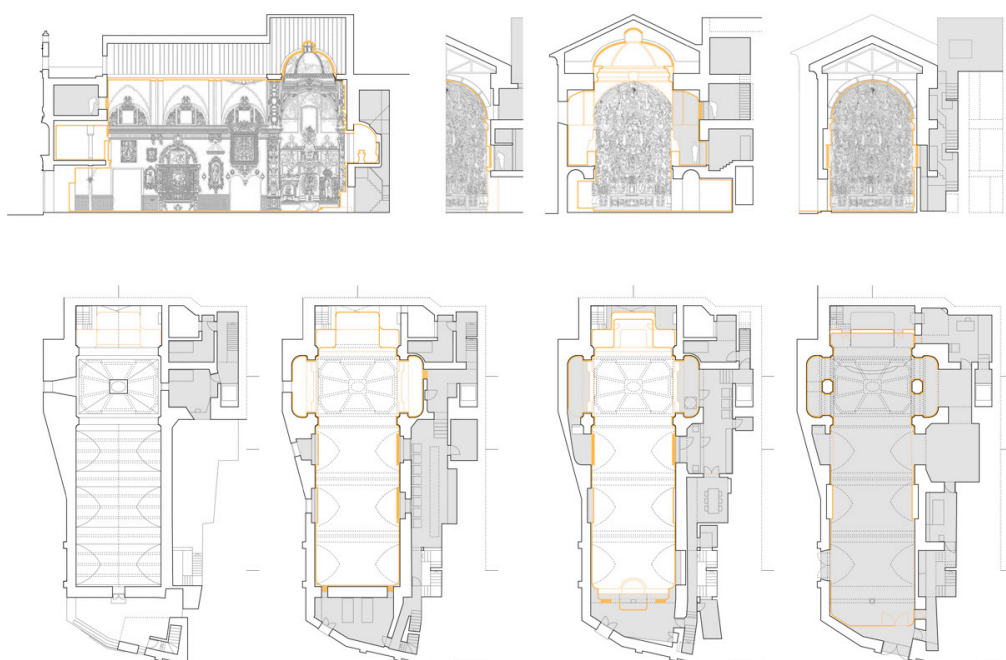

Fig. 9. La Capilla de San José, Sevilla, 2015. Espacios superpuestos: casa y capilla. La casa, como espacio doméstico ocupado por los Capuchinos. La capilla, como vacío y patio dorado interior. Levantamiento planimétrico inédito elaborado por el autor, 2016.

modernidad no es el espacio visible, no es aquello que vemos ante nuestros ojos, sino el espacio oculto. El espacio oculto es lo que queda después de que la modernización haya seguido su curso o, más concretamente, lo que se coagula en el espacio visible mientras la modernización está en marcha, suhermosa secuela (García, 2018)(figura9).

Permítanme recrearme, por tanto, con esta otra Sevilla nacida de la oscuridad, la ficción y el idealismo; una ciudad que bien podría ser imaginaria, superpuesta a la real, encarnada en su misma entraña, desplazada a ese otro mundo de lo alegórico e imaginario. Una Sevilla que, es más, mucho más de lo que vemos, que el conjunto físico de monumentos, edificios nobles y caserío doméstico. Me gustaría pensar que este relato les hará soñar con esa otra ciudad, aquella que se oculta en el trasfondo de lo que para muchos es su imagen real. Es la vivencia que a lo real superpone -transfigurándolo- lo imaginario, ligando la luz con la oscuridad, los vivos con los muertos y a éstos con los que aún no han nacido. Una ciudad oculta, convertida en parte de las personas sin saberlo, hecha carne y sangre con ellas, metida bajo su misma piel, ya definitivamente oculta e imaginaria. "Esta sucesión de acontecimientos emocionales y sensoriales que la ciudad nos brinda", afirmaba Chaves Nogales (2011, p. 51) en La ciudad, obra dedicada a Sevilla, "nos hace caminar por ella con los ojos cerrados".

Confieso que, desde hace años, busco con obsesión estos espacios en los que la oscuridad viene de dentro, lugares en los que una luz negra emana del núcleo interior de la materia. Esta especie de interés obsesivo por los espacios ocultos de nuestra ciudad, ha derivado en una investigación llena de sorpresas; una especie de 
portulano, de cosmografía de otros mundos que está disponible para su consulta en la Sala de Documentos Especiales de la biblioteca de la Escuela Técnica Superior de Arquitectura de Sevilla (García, 2017)3. . Deseo que este ensayo estimule al lector, despertando en él la curiosidad necesaria para acercarse y tocar, para tener entre sus manos el objeto original.

Un trabajo que muestra de manera sugestiva los descubrimientos realizados en la cara oculta de esta ciudad, y que van desde los "espacios negros" al "sonido de las sombras", pasando por, entre otros, "mapas para la desorientación" y "lo otro, la cara oculta". Relatos personales, experiencias compartidas, referencias provenientes de otros mundos y culturas, que se presentan a través de la reflexión que avanza la narrativa de sus textos, el discurso de los dibujos y las fotografías realizadas por el autor en sus incursiones en la oscuridad.

Descubrirá el lector al adentrarse sigilosamente en sus dibujos, la singularidad y el carácter transversal de los casos de estudio, así como su conocimiento exhaustivo, resultado de la dilatada investigación del archivo documental creado. Disfrutará al encontrarse inmerso entre los muros de la Catedral de Sevilla, a modo de deriva literaria, que se centra en la experiencia que supuso la deambulación libre por los intersticios de esta enorme ciudadela de piedra. Una exploración iniciada en 1989, como estudiante de Arquitectura, y concluida en estos años con motivo de esta investigación. Con la complicidad de Jaime Navarro Casas, arquitecto mayor de la Catedral, el que esto escribe, se sumergió durante meses en tres tesoros ocultos: la pequeña escalera tallada en el muro de la Sala Capitular; el interior del Órgano de la Epístola, y la grieta junto a la Capilla de la Granada, límite entre las obras góticas y almohades. Tres experiencias inéditas con las que completar la planimetría oficial del edificio: un artilugio de luz, una máquina de vientos y un lienzo que captura sombras.

Trayectorias y derivas guiadas en ocasiones por verbos, y otras por líneas que parecen escritas con un escalpelo. En el convento sevillano de Santa Clara, entre naranjos y una fuente de mármol, hemos descubierto un espacio secreto, una habitación oscura que no aparece dibujada en ninguno de los planos consultados. Hace tiempo las monjas del convento no eran enterradas. La cama donde dormían estaba compuesta de tres tablas longitudinales. Cuando morían, las dos laterales se giraban en vertical y en esa parihuela eran depositadas en un banco de fábrica, corrido a lo largo de las paredes del pudridero; una inquietante habitación que era tapiada después de cada entierro. Cuando se producía un nuevo fallecimiento, esta sala era devuelta al mundo visible, los albañiles abrían el cuarto y eran retirados

3 Tesis doctoral inédita, Universidad de Sevilla, Sevilla, 2017. Premio Extraordinario de Doctorado, Primer Premio IUACC a la mejor tesis doctoral leída en universidades españolas, 2017. Un facsímil de la tesis doctoral fue adquirido por la Biblioteca de la Universidad de Sevilla en septiembre de 2018, y está disponible para su consulta en la Sala de Documentos Especiales (en B Arquitectura_Q Tesis GAR car). 


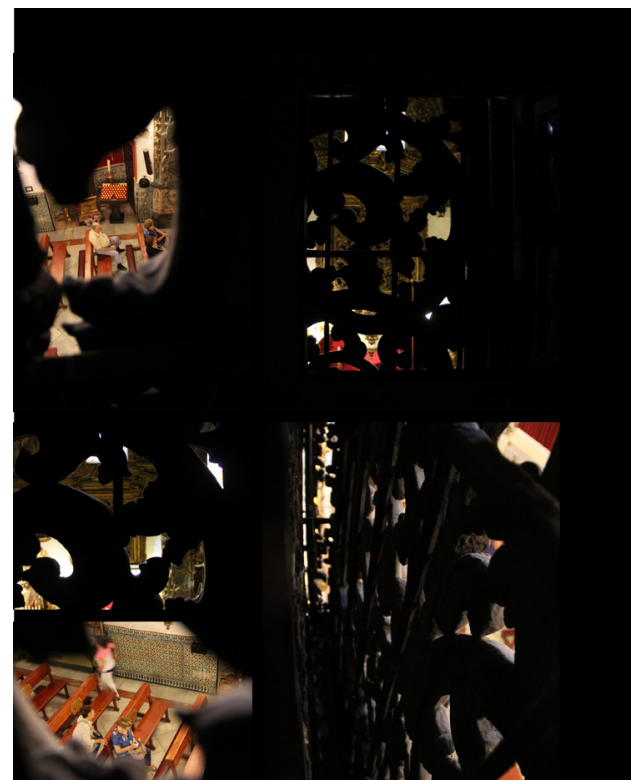

Fig. 10. La Capilla de San José, Sevilla, 2015. Experiencias desde lo oculto, fotografias tomadas por el autor, 2016.

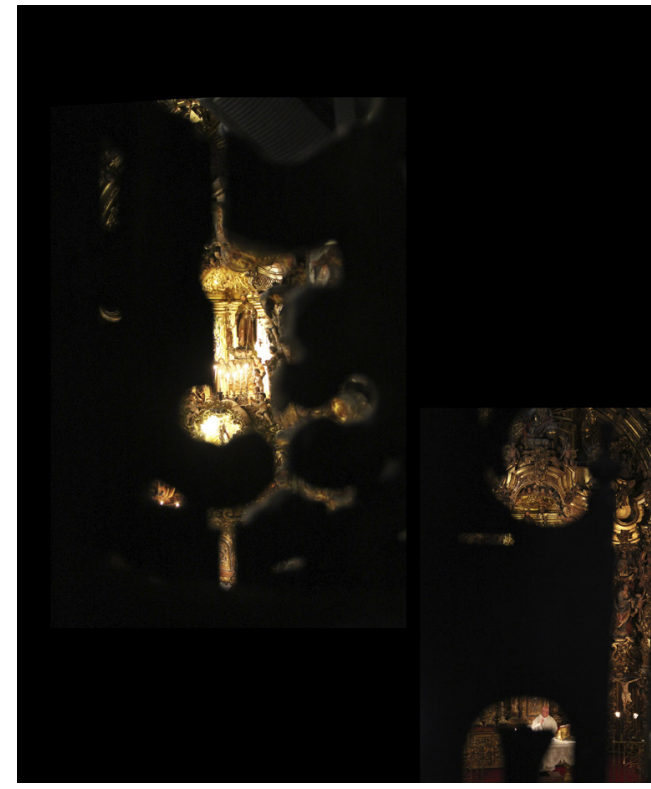

Fig. 11. La Capilla de San José, Sevilla, 2015. Experiencias desde lo oculto, fotografias tomadas por el autor, 2016.

los restos yacentes al osario común. Hay días que aún parece oírse un murmullo de pisadas enterradas. Durante las semanas que estuvimos buscando este espacio, me quedaba paralizado tratando de descubrir su huella; detrás de qué pared encalada se encontraba este enorme secreto.

Cartografías del espacio oculto es, al fin y al cabo, además de un ilustrado atlas de amor por la arquitectura de nuestra ciudad, un libro de autopsias y vivisecciones; y es también un libro de viajes: el relato espiral de un viaje que, quiere pensar el que esto escribe, aún no ha terminado (figuras 10 y 11).

\section{CON LOS OJOS CERRADOS, A MODO DE CONCLUSION ABI- ERTA}

En sus Seis propuestas para el Próximo Milenio, el escritor Italo Calvino (1998, p. 22) afirmaba que "la fantasía es un lugar donde no hay Luz". Ninguna frase mejor para concluir este relato, para definir estos espacios como laboratorios para nuestra imaginación y nuestros sentidos, donde la luz no puede existir. Este ensayo sugiere una idea para un tiempo rebosante de imágenes: no usar los ojos. Porque no tener ojos es como no tener nada, e ir a ciegas no significa no ver, sino hacerlo con las 
Experiencias ocultas: sobre lo humano... - T. García y F. J. Montero-Fernández

manos o el oído, el gusto y el olfato, que es la mejor manera posible de ver las cosas de verdad.

Apagar deliberadamente nuestros ojos nos ha llevado a olvidar los pasos que anticipaban las conductas, los caminos de la memoria. Memorias de un nómada que han abierto en nuestro trabajo itinerarios con los que habitar lugares intermedios y ocultos de nuestra ciudad, llenos de vida y de sorpresas. Cuando se perciben estos lugares hay que detenerse, afianzar las manos para llenarse de sensaciones. Ver sin los ojos significa hacerlo hacia dentro, reconocerse en lo que te rodea, como algo tuyo, íntimo y cercano. Por eso la emoción de hallar sin los ojos supone un momento de vida compartida, donde tú eres lo otro, donde el cuerpo queda suspendido en ese espacio negro que es eterno. Moverse sin los ojos nos llevará a pensar sin ellos, y cuando esto ocurre, todo es nuevo, todo aparece por primera vez, nace y muere en ese instante. Esta investigación ha permitido que aparezcan nuestros sentidos; aparece el espacio oculto, y con él, el cuerpo (Mendes, 2007, p. 36).

Sin ojos hemos descubierto el movimiento articulado de nuestro cuerpo en el espacio, sintiendo los elementos rítmicos y fluidos que lo habitan. Sin ojos no quiere decir a ciegas, es más bien el límite entre la visión y la ausencia de percepción sensorial. Un estado donde se puede estar sin llegar a estar del todo; mapas para una desorientación con la que hemos llegado a sentir las energías del espacio oculto, y a los dioses que habitan en ellos. Sin los ojos hemos tenido que fijar la atención en los matices, en aquello que no se ve, pero si se escucha, o se huele; hemos llegado a sentir los cambios de temperatura en el interior de un muro o la caricia del viento (Muñoz, 2018, p. 47).

Así pues, abordar como vía de conocimiento y mecanismo proyectual estos procesos de configuración formal, junto a un desarrollo adecuado metodológicamente en cuanto a referentes y objetivos, inserta este trabajo plenamente en los procesos de investigación e innovación que la sociedad y la universidad reclaman de sus investigadores. La investigación no se limita a la mera presentación de los modelos, sino que los activa creativamente, devolviendo el resultado de la experiencia al archivo del conocimiento.

Porque con los ojos cerrados se divisan infinitos campos (Vega, 2009, p. 44), la humanidad necesita entender y buscar estos mundos desdoblados, hechos de amalgamas sombrías y concavidades oscuras que reclaman la experiencia de ver y dejar de ver, seduciéndonos con la idea de lograr una especie de ceguera inducida, de ver con los ojos cerrados. Esta es la historia de una obsesión por encontrar un punto de quietud, una zona exenta de preocupación, un hueco donde sentirse seguro. Tal vez encontremos allí, en ese espacio desdoblado del mundo visible, un nuevo lugar desde el que observar y entender la escala del espacio; esto es, el modo según el cual los otros establecen relaciones de semejanza, distancia o proximidad con uno mismo. 
Quizás, el tiempo consiga reconstruir la intimidad de lo desvelado.

\section{BIBLIOGRAFIA}

Calvino, I. (1998). Seis propuestas para el próximo milenio. Madrid: Siruela.

Chaves, M. (2011). La ciudad. Sevilla: Almuzara.

Colomina, B. (2006). Doble exposición. Madrid: Akal.

Cruz Isidoro, F. (2015). La capilla de san José del gremio de carpinteros de lo blanco. Sevilla: Diputación de Sevilla.

Garcia, T. (2017). Cartografias del espacio oculto. Laboratorio de experimentación arquitectónica (Tesis doctoral inédita). Universidad de Sevilla, Sevilla.

Garcia, T. (2018). Cartografias del espacio oculto. Sevilla: Universidad de Sevilla.

Gopegui, B. (2009). Las escalas de los mapas. Madrid: Anagrama.

Holl, S. (2011). Cuestiones de percepción: fenomenología de la arquitectura. Barcelona: Gustavo Gili.

Mccall, S. (2006). Il club dei filosofi dilettanti. Milán: Guanda.

Muñoz, M. (2018). Escritos sobre la invisibilidad: arquitectura y ocultación. Madrid: Abada.

Mendes, M. (2007). Camuflaje: engaño y ocultación en el arte contemporáneo. Madrid: Siruela.

Parra, J. (2020). Tomás García García: Cartografías del espacio oculto. Welbeck Estate en Inglaterra y otros espacios. Proyecto, Progreso, Arquitectura, n. 22, pp. 164165. DOI: https://doi.org/10.12795/ppa.2020.i22.11

Pérez Escolano, V. y Sierra Delgado, J. S. (directores). (1968). Sobre la Capilla de San José de Sevilla [documental inédito]. España.

Vega, A. (2009). ¿Y si pongo una palabra?. Madrid: Demipage. 
